\title{
Direct and reflex responses in perineal muscles on electrical stimulation
}

\author{
DB VODUŠEK, M JANKO, J LOKAR \\ From the Institute for Clinical Neurophysiology, University Medical Center, ${ }^{*}$ Ljubljana, Yugoslavia
}

SUMmARY Responses in the external anal and urethral sphincters as well as in the bulbocavernosus muscle have been evoked by supramaximal electrical stimulation of the penis (or clitoris), perineum and the peri-anal region and recorded electromyographically in 82 male subjects 5 to 73 years old and in nine female subjects 18 to 55 years old, who had no systemic diseases or demonstrable sacral nervous system lesion. On perineal stimulation (including the penis or clitoris) reflex responses with a typical latency of $33 \mathrm{~ms}$ and which exhibit no habituation were obtained in all muscles examined. Stimulation of the peri-anal region gave habituating reflex responses with a typical latency of $55 \mathrm{~ms}$ in all muscles examined. On perineal, and sometimes also peri-anal stimulation, stable short latency responses with typical latencies of 5 and $13 \mathrm{~ms}$ were recorded; both were considered to be direct responses. The different evoked muscle responses obtained by stimulation in the perineal and peri-anal region have to be distinguished when the bulbocavernosus and anal reflexes are recorded for evaluation of sacral nervous system lesions.

The need for evaluation of the sacral nervous system arises in various clinical conditions, commonly with disorders of micturition, defaecation and erectile impotence. Apart from the usual clinical examination, neurophysiological procedures have been introduced to provide more detailed information about the functional status of structures supplied by sacral segments of the spinal cord. Electromyography of external sphincter muscles is established $^{1-4}$ and measurement of pudendal nerve motor conduction velocity ${ }^{5}$ and sacral roots conduction velocity ${ }^{6}$ have been reported.

The functional status of the reflex arcs subserving the lower sacral segments as a whole can be assessed by eliciting the bulbocavernosus ${ }^{7}$ and the anal reflexes. While the bulbocavernosus reflex has been reported to be unreliable,$^{8}$ later reports ${ }^{7}{ }^{10}$ have shown the clinical usefulness of this reflex and the reliability of EMG records of the reflex response. Rushworth ${ }^{11}$ introduced electrical stimulation of the glans penis and reported a latency of $35-40 \mathrm{~ms}$ of the electromyographically recorded reflex response in the bulbocavernosus muscle. Using the same tech-

\footnotetext{
Address for reprint requests: David B Vodusek, MD, Institute for Clinical Neurophysiology, University Medical Center, Zaloska 7, 61105 Ljubljana, Yugoslavia.
}

Received 16 June 1982 and in revised form 20 September 1982. Accepted 1 October 1982. nique, Ertekin and Reel ${ }^{12}$ reported a mean value of $36.1 \mathrm{~ms}$ in 14 healthy males and similar values have since been formed by other authors. ${ }^{13-15}$

Pedersen $^{16}$ reported a reflex response in the external anal sphincter with a mean latency of $50 \mathrm{~ms}$, obtained by electrical stimulation of the peri-anal skin in 30 healthy subjects; a simultaneous reflex response could be recorded in the external urethral sphincter in ten subjects studied. Similar findings were reported by Vodušek et al.$^{15}$ Henry and Swash ${ }^{17}$ reported an early anal reflex response with a mean latency of $8.9 \mathrm{~ms}$ in 13 healthy subjects. A preliminary report of Tørring, Pedersen, Klemar and Schrøder ${ }^{18}$ described two short latency responses in the external anal sphincter muscle previous to the 50 ms reflex reponse. Since all authors eliciting "sacral reflexes" have claimed that they are clinically useful, this topic needs further clarification.

\section{Subjects and methods}

Eighty-two male subjects 5 to 73 years old (mean age 29.3 + 14.9 SD) and nine female subjects 18 to 55 years old were examined. They were referred for neurophysiological evaluation because of pain problems (pains in the groin or back, dysuria, coccigodynia), premature ejaculation and enuresis. The patients with enuresis had normal findings on urodynamic testing. All patients had a neurological examination as well as EMG studies of pelvic floor muscles with normal results. In particular, all had the anal reflex; all the 
males had the bulbocavernosus reflex and the sensation in sacral dermatomes was intact in everyone. The recordings were made with a Medelec MS6 EMG apparatus and concentric EMG needles inserted into the bulbocavernosus muscle and the external urethral and anal sphincters that were reached by the standard percutaneous approach. ${ }^{1} \mathrm{~A}$ bipolar surface electrode (Disa 13462) was used for stimulating the penis (or clitoris), the lateral perineal region and the peri-anal region. The electrodes were applied to the dorsal aspect of the penis with the anode lying at the base of the glans and the cathode proximal to the anode. Supramaximal single stimuli of $0.2 \mathrm{~ms}$ duration were applied with a frequency of $0 \cdot 2-5 \mathrm{~Hz}$, or randomly. The latency of evoked responses was measured to the first deflection and approximated to the first higher millisecond (to the first higher tenth of a millisecond in short-latency responses). Recordings were made from different sites in the muscle and the response with the shortest latency was accepted. For various reasons all subjects were not examined for all of the reported evoked responses.

\section{Results}

Electrical stimulation of the penis elicited reflex reponses which were detected in the bulbocavernosus muscle (fig 1), external urethral sphincter muscle and external anal sphincter muscle. Stimulation of the clitoris produced the same type of evoked responses in the external urethral and anal sphincter muscles. Increasing stimulus voltage increased the amplitude and decreased the latency of the evoked responses. Care was taken to stimulate with supramaximal stimuli, which were occasionally described as unpleasant, but never as painful. The recordings from the bulbocavernosus muscle were always straightforward; they never showed spontaneous activity of motor units at rest. The responses in the external urethral and anal sphincters usually overlaid some background activity, which tended to build up on repeated stimulation; random stimulation and averaging of responses were therefore often required to obtain an identifiable response. The mean latencies of these reflex responses for our group of adults are given in the table. In six boys who were 5 to 14 years old a mean latency of 30.5 (SD \pm $3.3 \mathrm{~ms}$ ) was obtained with a range from 25 to $36 \mathrm{~ms}$.

Stimulating the perineal region about $2 \mathrm{~cm}$ anteriorly to the anal aperture elicited the same type of response as that produced by stimulating the penis (or clitoris) but a slightly shorter latency was usually obtained. On the other hand, the applied stimuli usually had to be stronger. We called the reflex response obtained by stimulation of the penis, clitoris and perineum the $\mathrm{R} 3$ response.

Strong electrical stimuli to the perineal or the perianal region also produced an early evoked muscle response in the bulbocavernosus, external urethral sphincter and external anal sphincter muscles with
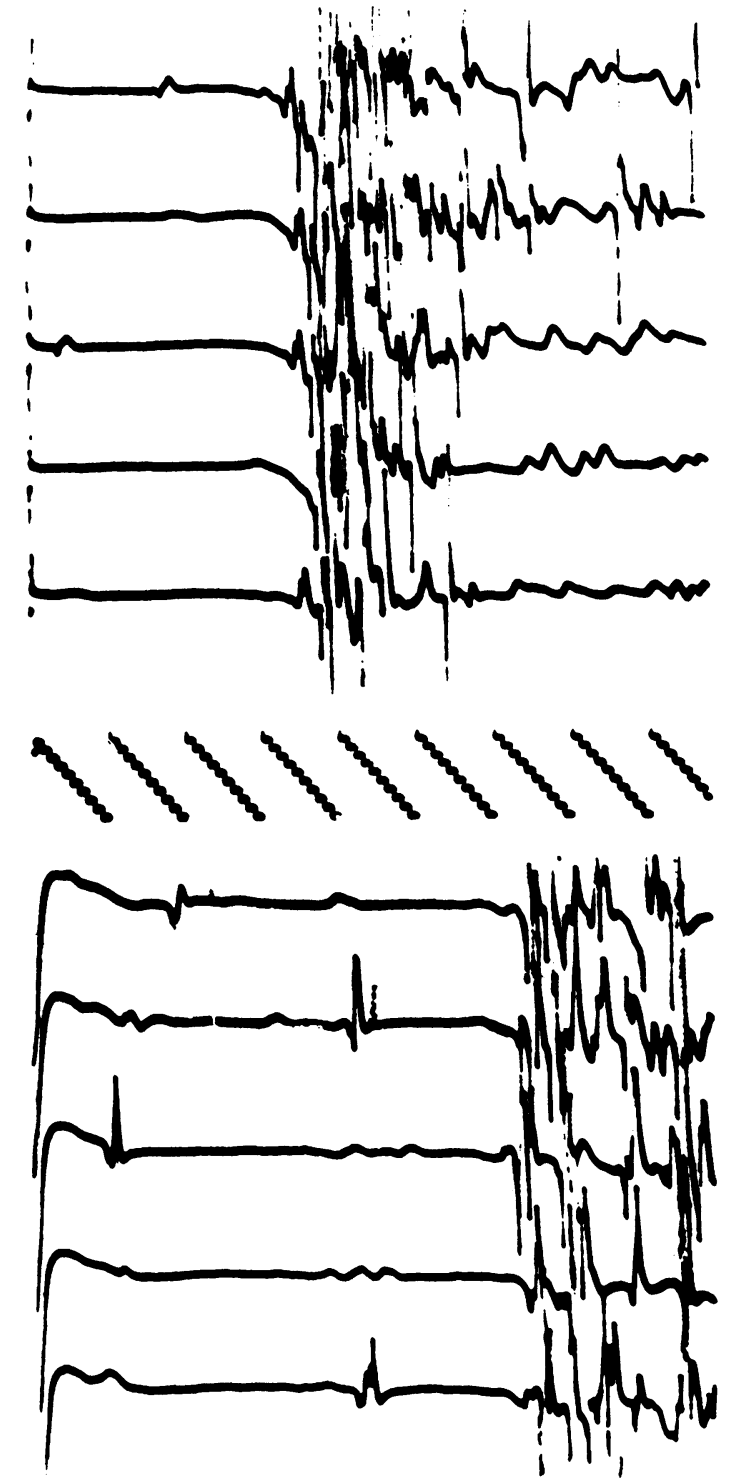

Fig 1 Recordings of reflex responses in the bulbocavernosus muscle. Above is the $R 3$ response on penile stimulation, below the $R 4$ response on peri-anal stimulation. Calibration: $500 \mu \mathrm{V}, 10 \mathrm{~ms}$ per division.

latencies from 2.6 to $8.0 \mathrm{~ms}$ (table, fig 2 ). In four subjects this response was not seen, probably because of a large stimulus artefact; in six others the response was seen but an exact onset for measurement of the latency could not be ascertained. This type of response, which we called the $\mathrm{R} 1$ response, could usually be elicited in the external anal sphincter with perineal or peri-anal stimulation. The duration 
Table 1 Direct and reflex responses in perineal muscles in adults*

\begin{tabular}{|c|c|c|c|c|c|}
\hline & & $\begin{array}{l}\text { Number of } \\
\text { subjects }\end{array}$ & $\begin{array}{l}\text { Mean } \\
(m s)\end{array}$ & $\begin{array}{l}\text { Standard } \\
\text { deviation }\end{array}$ & $\begin{array}{l}\text { Range } \\
\text { (ms) }\end{array}$ \\
\hline External anal sphincter & $\begin{array}{l}\text { R1 }{ }^{\dagger} \\
\text { R2 } \dagger \\
\text { R3 (M) } \\
\text { R3 (F) } \\
\text { R4† }\end{array}$ & $\begin{array}{r}29 \\
9 \\
14 \\
1 \\
71\end{array}$ & $\begin{array}{r}4 \cdot 9 \\
13 \cdot 2 \\
35 \cdot 2 \\
34 \cdot 0 \\
56 \cdot 0\end{array}$ & $\begin{array}{l}1 \cdot 13 \\
0.75 \\
4 \cdot 60 \\
\overline{8.47}\end{array}$ & $\begin{array}{l}2 \cdot 6-7 \cdot 1 \\
11 \cdot 6-14 \cdot 1 \\
28 \cdot 0-44 \cdot 0 \\
- \\
38 \cdot 0-83 \cdot 0\end{array}$ \\
\hline External urethral sphincter & $\begin{array}{l}\text { R1 } \neq \\
\text { R3 (M) } \\
\text { R3 (F) } \\
\text { R4 } †\end{array}$ & $\begin{array}{r}16 \\
14 \\
8 \\
7\end{array}$ & $\begin{array}{r}5 \cdot 1 \\
33 \cdot 0 \\
33 \cdot 6 \\
55 \cdot 1\end{array}$ & $\begin{array}{l}1.45 \\
3.90 \\
3.46 \\
6.84\end{array}$ & $\begin{array}{r}3 \cdot 0-8 \cdot 0 \\
26 \cdot 0-40 \cdot 0 \\
29 \cdot 0-39 \cdot 0 \\
48 \cdot 0-68 \cdot 0\end{array}$ \\
\hline Bulbocavernosus muscle & $\begin{array}{l}\text { R1 } \neq \\
\text { R3 }(M) \\
\text { R4† }\end{array}$ & $\begin{array}{r}11 \\
60 \\
9\end{array}$ & $\begin{array}{r}4 \cdot 7 \\
32 \cdot 3 \\
53 \cdot 2\end{array}$ & $\begin{array}{l}1.70 \\
3.94 \\
3.70\end{array}$ & $\begin{array}{r}2 \cdot 8-7.4 \\
23 \cdot 0-41 \cdot 0 \\
50 \cdot 0-60 \cdot 0\end{array}$ \\
\hline
\end{tabular}

* Mean age $33 \cdot 2 \pm 7 \cdot 3$ years.

R3- bulbocavernosus reflex response; $R 3(M)$ are the responses on penile stimulation; $R 3(F)$ are the responses on clitoral stimulation. R4- anal reflex response.

$\dagger$ Stimulated peri-anally.

$\ddagger$ Stimulated in the perineum.

of the $\mathrm{R} 1$ response was from $5 \mathrm{~ms}$ to as long as $30 \mathrm{~ms}$ in some external anal sphincters. Once a supramaximal stimulus was applied the shape of the first 5-10 ms of this response was very stable and did not change significantly on increasing the stimulus rate to $5 \mathrm{~Hz}$.

In nine out of 33 subjects a discrete evoked muscle response was recorded in the external anal sphincter with a latency of 11.6 to $14.1 \mathrm{~ms}$ (mean $13.2 \mathrm{~ms}$ ). This response followed the short latency $R 1$ evoked muscle response and was called the $\mathrm{R} 2$ response. The latency of the $\mathbf{R} 2$ response was easier to ascertain when the stimuli used were not supramaximal, so that the $\mathrm{R} 1$ response did not reach its maximal amplitude (fig 3). The long duration R1 responses described above are believed to be a complex response with the $\mathrm{R} 2$ component blending into the $\mathrm{R} 1$ component and sometimes even $R 1, R 2$ and $R 3$ responses blended together.

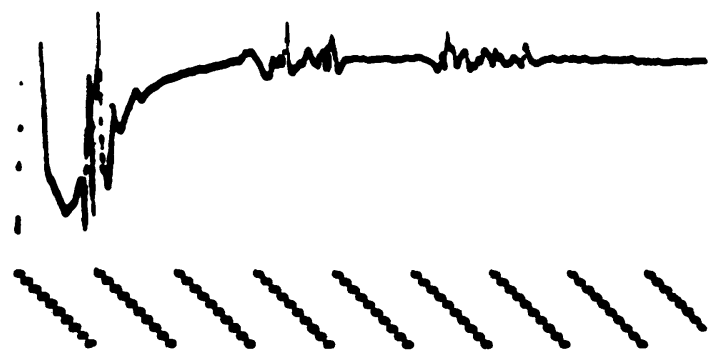

Fig 2 On stimulation in the anterior peri-anal region a direct $(R 1)$ response as well as both $R 3$ and $R 4$ reflex responses could be elicited in the bulbocavernosus muscle. Calibration: $1 \mathrm{mV}, 10 \mathrm{~ms}$ per division.
On peri-anal stimulation, a long latency reflex response was obtained in the bulbocavernosus, external urethral and anal sphincters which on increase of stimulus voltage increased in amplitude and decreased in latency to a minimum value of 38 to $83 \mathrm{~ms}$ (table, fig 1). The threshold for this reflex response, which was called the $\mathrm{R} 4$ response was higher than that for the $\mathrm{R} 3$ response. The stimulation required to produce the $\mathrm{R} 4$ response was usually perceived as unpleasant, often as painful and the response tended to habituate even on regular stimulation of $0.5 \mathrm{~Hz}$ (in the sphincter muscles the longlasting increase in tonic activity after stimulus tended to obscure this habituation). The $\mathrm{R} 4$ response could be obtained with insignificant changes in latency on both ipsilateral and contralateral peri-anal stimulation and the response on contralateral side often showed less stimulus artefact. When the stimulating electrode was moved anteriorly in the para-anal region both $\mathrm{R} 3$ and $\mathrm{R} 4$ responses could be recorded, sometimes even R1, R3 and R4 (fig 2). By moving the stimulating electrode more anteriorly only the R3 response was left of the longer latency responses.

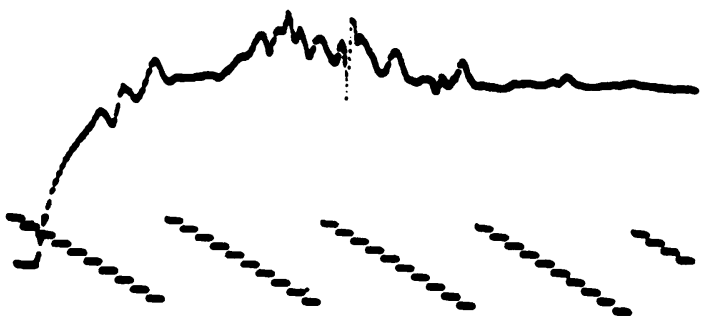

Fig 3 Two short latency responses ( $R 1$ and $R 2)$ in the external anal sphincter on peri-anal stimulation. Calibration: $1 \mathrm{mV}, 10 \mathrm{~ms}$ per division. 
With a particular position of the stimulating electrode $\mathrm{R} 1$ responses only (without a reflex response) could be sometimes obtained in the external anal sphincter.

In conclusion: both the $\mathrm{R} 3$ and $\mathrm{R} 4$ responses could be recorded in all examined muscles in all subjects in whom they were sought by using different stimulation sites. The $\mathrm{R} 1$ response could not be seen (due to stimulation artefact) in four out of 39 examined subjects.

Applying the technique to two patients with myelomeningocele who had no sensation in the perineal area as well as signs of a partial denervation in the pelvic floor muscles, we were able to detect a small amplitude R1 and no R3 or R4 in the external anal sphincter and bulbocavernosus muscles.

\section{Discussion}

Direct responses in the external urethral sphincter muscle and the external anal sphincter muscle have been recorded on pudendal nerve stimulation close to the ischiadic spine by needle electrode ${ }^{5}$ with average latencies of $5.1 \mathrm{~ms}$ (for external urethral sphincter) and $5.5 \mathrm{~ms}$ (for external anal sphincter), which corresponds well to the latencies of our R1 response. Using concentric EMG and single fibre EMG needle electrodes Trontelj et $a l^{19}$ have detected direct responses with latencies up to $10 \mathrm{~ms}$ from the levator ani muscle on stimulating with needles inserted into the same muscle (presumably stimulating intramuscular nerve branches). Stimulating sacral roots at the level of the $S_{3}$ or $S_{4}$ sacral foramen (using needle electrodes) Jelasic et $a^{6}$ have obtained direct responses in the external urethral and anal sphincter muscles with a latency between 3 and $5 \mathrm{~ms}$ for a distance between 8 and $11 \mathrm{~cm}$. On stimulating the peri-anal skin with surface electrodes, Tørring $e t$ $a l^{18}$ have described two short-latency responses (with latencies 2-8 ms and 13-18 ms respectively), which were generally stable on repeated stimulation. Our results show the same grouping of shorter latency responses (which we called the $\mathrm{R} 1$ and $\mathrm{R} 2$ responses in the recordings). The $\mathrm{R} 1$ and $\mathrm{R} 2$ responses have a stable shape, show no habituation and were shown by Tørring $e t a^{18}$ to be unaffected by epidural anaesthesia. Similarly, we have been able to record an R1 response but no bulbocavernosus or anal reflex responses in two patients with myelomeningocele, who lacked sensation in the peri-anal region. The R1 can thus be interpreted as a direct response, and so can probably the $\mathrm{R} 2$, considering that the external anal sphincter receives motor innervation both from the inferior rectal nerve and the perineal nerve,$^{20}$ and both possibly could have been stimulated simultaneously. $\mathrm{H}$ - and F-type responses were described in the levator ani muscle with latencies of about $30 \mathrm{~ms},{ }^{19}$ longer than the latency of the R2 response. Henry and Swash ${ }^{17}$ have reported what they termed the anal "reflex" in the external anal sphincter with a mean latency of $8.9 \mathrm{~ms}(6.9-11.5 \mathrm{~ms})$ obtained by peri-anal stimulation. It would appear that they recorded the previously mentioned short latency responses, not observing the longer latency reflex responses; the opposite occurred when Pedersen $e_{t}$ $a l^{16}$ reported on human anal reflexes, detecting the short latency responses only later. ${ }^{18}$

Since Rushworth" described the electromyographically recorded bulbocavernosus reflex on electrical stimulation of the penis several authors have provided values obtained from a rather small number of normal men. Our mean value for this socalled bulbocavernosus reflex (our R3 response) is somewhat lower than that reported by Ertekin and Reel $^{12}$ for $14 \mathrm{men}$ ( $36.1 \mathrm{~ms}$, range $27.5 \mathrm{~ms}$ to $42.5 \mathrm{~ms}$ ) and Siroky et $\mathrm{ll}^{14}$ for 9 (?) men (35 ms, range 28-42). This might be partly due to our search for the shortest latency reflex response in different sites of the muscle. We have consistently found reflex responses in the external urethral sphincter as well as the external anal sphincter. Others have observed such responses in only $21 \%$ of normal subjects. ${ }^{12}$ Recording from different sites of a single bulbocavernosus muscle gave up to $2 \mathrm{~ms}$ difference in reflex latency readings, which might be partly due to difficulties in determining the onset of the reflex response. Therefore we should be cautious in interpreting side to side differences as indicators of spinal cord delays. ${ }^{14}$ It is interesting to note that Dick $e t a l^{11}$ have recorded from the bulbocavernosus muscle what they called "nerve action potentials" with latencies from 29 to 40 ms. These were recorded following electrical stimulation of the penis and of the anterior urethra. The shortest reflex responses that Trontelj et al ${ }^{19}$ detected from levator ani muscle on stimulation with needle electrodes in the same muscle had the latency of 35 ms which corresponds with our $\mathrm{R} 3$ response.

Pedersen $e t a l^{16}$ reported EMG recordings of the anal reflex responses on electrical peri-anal stimulation. In 30 subjects they obtained a mean value of 50 $\mathrm{ms}(\mathrm{SD} \pm 10.5 \mathrm{~ms})$ for the anal reflex latency, which is slightly shorter than our values for the $\mathrm{R} 4$ response. It was also our experience that the reflex response could be recorded in all subjects, but we had occasional difficulty in determining the exact onset of the response (despite using random stimuli and averaging technique). The wide spread of recorded latencies makes the anal reflex latency determination less useful in an actual search for slight lesions of the sacral portion of the nervous system.

Both the bulbocavernosus (R3) and the anal reflex (R4) have much longer latencies on threshold 
stimulation. Other investigators have noted that the bulbocavernosus reflex showed little habituation;12 14 this is also our experience. The shortest latency R3 response might well include few interneurons. The anal reflex, however, shows marked habituation which together with its longer latency speaks for a larger complexity of interneuron connections subserving the R4 response. The afferent limbs of the two reflex pathways may be different as well. The relatively low strength stimulus necessary for eliciting the bulbocavernosus reflex depolarizes probably mostly A beta fibres (in the dorsal penile nerve), whereas the depolarisation of A delta fibres might be necessary for eliciting the nociceptive anal reflex; certainly the threshold for the latter is higher. In this context it is interesting to note the socalled "electromyelography" 2 -reflex responses recorded in the external anal sphincter muscle on electrical stimulation of the bladder neck. The latencies of this reflex, which has a visceral afferent limb, are between $50-80 \mathrm{~ms}^{22} 23$

\section{Conclusion}

In conclusion, direct responses from the bulbocavernosus and the external sphincter muscles can be detected by electrical stimulation of the pudendal nerve branches in the perineal region with a typical latency of $5 \mathrm{~ms}$. Additional responses with a typical latency of $13 \mathrm{~ms}$ are sometimes observed in the external anal sphincter muscle and they are probably direct responses, too. Oligosynaptic reflex responses with a typical latency of $33 \mathrm{~ms}$ and which exhibit no habituation can be obtained by nonpainful electrical stimulation of the perineal region, including the penis, clitoris and the anterior urethra. Polysynaptic, habituating responses with a typical latency of $55 \mathrm{~ms}$ can be obtained by strong (usually painful) electrical stimulation of the peri-anal region. The detection of both direct and reflex responses is a valuable addition to an EMG examination of muscles innervated by the S2-S4 segments.

This study was supported by the Research Community of Slovenia, Yugoslavia, and Bob and Vivian Smith Foundation Houston, Texas.

\section{References}

${ }^{1}$ Jesel M, Isch-Treussard C, Isch F. Electromyography of striated muscle of anal and urethral sphincters. Desmedt JE ed. New Developments in Electromyography and Clinical Neurophysiology 1973;2:40620.

${ }^{2}$ Chantraine A. EMG examination of the anal and urethral sphincters. Desmedt JE ed. New Developments in Electromyography and Clinical Neurophysiology 1973;2:421-32.
${ }^{3}$ Allert ML, Jelasic F. Diagnostik neurogener Blasenstörungen durch Electromyographie. Stuttgart: Thieme 1974.

${ }^{4}$ Pedersen E. Electromyography of the sphincter muscles. Cobb WA, Van Duin H eds. Contemporary Clinical Neurophysiology 1978;EEG Suppl. No. 34:405-16.

${ }^{5}$ Chantraine A, DeLeval J, Onkelinx A. Motor conduction velocity in the internal pudendal nerves. Desmedt JE ed. New Developments in Electromyography and Clinical Neurophysiology, Basel: Karger 1973;2:433-8.

6 Jelasic F, Fischer D, Allert ML. Diagnosis of neurologic disorders of micturition without evidence of the pathological process by measuring conduction velocity of sacral roots. Urol Int 1975;30:100-2.

${ }^{7}$ Bors E, Blinn KA. Bulbocavernosus reflex. J Urol 1959;82:128-30.

${ }^{8}$ Rattner WH, Gerlaugh RL, Murphy JJ, Erdman WJ. The bulbocavernosus reflex: I. Electromyographic study of normal patients. J Urol 1958;80:140-1.

${ }^{9}$ Pierce JM, Roberge JT, Newmann MM. Electromyographic demonstration of bulbocavernosus reflex. J Urol 1960;83:319.

${ }^{10}$ Blaivas JG, Zayed AAH, Labib KB. The bulbocavernosus reflex in urology: a prospective study of 299 patients. J Urol 1981;126:197-9.

${ }^{11}$ Rushworth G. Diagnostic value of the electromyographic study of reflex activity in man. In Widen L ed. Recent Advances in Clinical Neurophysiology, Electroencephalogr Clin Neurophysiol 1967;Suppl. 25:65-73.

${ }^{12}$ Ertekin C, Reel F. Bulbocavernosus reflex in normal men and in patients with neurogenic bladder and/or impotence. J Neurol Sci 1976;28:1-15.

${ }^{13}$ Vacek J, Lohman M. Bulbocavernosus reflex in diabetics with erectivity disorders, clinical and electromyographical study. Cas Lek Cesk 1977;116:1014-6.

${ }^{14}$ Siroky MB, Sax DS, Krane RJ. Sacral signal tracing: the electrophysiology of the bulbocavernosus reflex. J Urol 1979;122:661-4.

${ }^{15}$ Vodušek DB, Lokar J, Janko M. A study of neurophysiological methods for evaluation of erectile impotence. Zdrav Vestn 1981;50:703-7.

${ }^{16}$ Pedersen E, Harving H, Klemar B, Tørring J. Human anal reflexes. J Neurol Neurosurg Psychiatry 1978;41:813-8.

${ }^{17}$ Henry MM, Swash M. Assessment of pelvic floor disorders and incontinence by electrophysiological recording of the anal reflex. Lancet 1978;1:1290-1.

${ }^{18}$ Tørring, Pedersen, Klemar, Schrøder. Anal sphincter responses after peri-anal electrical stimulation. Proc XI Ann Meeting Internat Continence Soc, Stockholm, Sweden, 1981;150-1.

${ }^{19}$ Trontelj JV, Janko M, Godec C, Rakovec S, Trontelj M. Electrical stimulation for urinary incontinence. Urol Inter 1974;29:213-20.

${ }^{20}$ Williams PL, Warwick R. Gray's Anatomy. 36th ed. Edinburgh: Churchill Livingstone, 1980.

${ }^{21}$ Dick HC, Bradley WE, Scott FG, Timm GW. Pudendal Sexual Reflexes, Urology 1974;3:376-9.

${ }^{22}$ Bradley WE. Urethral electromyelography. J Urol 1972;108:563-4.

${ }^{23}$ Rockswold GL, Bradley WE. The use of evoked electromyographic responses in diagnosing lesions of the cauda equina. J Urol 1977;118:629-31. 